\title{
Psycholinguistic Model of Abductive Reasoning in Fiction Narrative Discourse
}

\section{Inna Livytska}

Ph.D. in Philology, Associate Professor, Post-Doctoral Research Scholar, e-mail: Inna.livytska@gmail.com orcid.org/0000-0002-8295-948X Researcher ID: A-1224-2016

Taras Shevchenko National University of Kyiv, Institute of Philology, Department of English Philology and Cross-Cultural Communication,14, Taras Shevchenko Blvd., Kyiv, Ukraine, 01601

\begin{abstract}
Aim: The paper aims at defining the role of abductive reasoning in the reader's interpretation of English fiction narrative text. Three research questions are defined as follows: (1) what is the nature of sign interpretation in its application to textual analysis? (2) what linguistic factors determine the use of abduction in the interpretation of signs? (3) how to apply abductive reasoning in the process of reading and interpretation in EFL teaching practice? Abduction is viewed here as a type of reasoning in the three-componential semiotic model of argument and as a deductive hypothesis, responsible for implicit meaning processing (Charles Peirce). Materials and Methods: The paper states the four-stage process of abduction to be a basic inquiry method of the reader on his way to fiction world interpretation. By providing a step-by-step analysis of patterns of abductive reasoning in a short story "Happy Endings" by Margaret Atwood, the paper conducts a textual analysis of narratives in terms of subjectivity theory of communication, reflecting the mechanisms of reader's manipulation with information as a dynamic semiotic process of interpretation, limited by habit (final interpretant).
\end{abstract}


Results: Results of the research of the mental operations employed by the reader while processing textual information proved a strong interrelation of reading with writing, and mental sub-processes and operations. As the empirical research shows, the process of conceptualization demands a higher level of cognitive maturity on the part of the reader/writer, as it presupposes "knowledge transforming" operations as opposed to "knowledge telling" strategy (Paltridge et. al. 2009: 20).

To represent this process schematically, scholars assign the reader/interpretant the central role in the process of triadic sign interpretation, as he makes the further interpretation possible by a reference to the environment (Scheibmayer 2004: 305). The interpretant (I) and Representamen (R1) refer to the same object $(\mathrm{O})$; as Representamen (R2) stands in the same relation to object, represented by Representamen (R1) and to the system (O2), where it acquires the functions of the observer (Sonnenhauser, 2008: 331).

Conclusions: The conclusions coming from this research lead to the recognition of the second-level (or third level) observer as a source of subjectivity. And subjectivity, in its turn, arises from the difference in interpretation of signs recognized and established by the observer (Maturana \& Varela, 1980). Thus, the process of differentiation by the observer is expected to fix the possible existence of other meanings, produced by the relations of the interpretant to the environment. This is the notion of thirdness. And, therefore, "sign situation", plays the role of marking the pairs of differentiation in semiotic interpretation of signs. And it is this differential potential of indexical components of signs, and not their relatedness of meaning, which makes communication dynamic.

Keywords: subjectivity; final interpretant; sign situation; context; abduction; inference; coda

\section{Introduction}

The problem of meaning embodiment in modern linguistics today demands a synergetic collaboration of all spheres of knowledge, engaged with the interpretation of language and signs. Charles Sanders Pierce, the father of abductive reasoning, asserted that human knowledge is determined by their prior 
knowledge, claiming that, "we have no power of Intuition" (Peirce, 1868: 141). By this, he meant that intuitions are not best guesses based on previous knowledge, as abductions are; stating that intuitions are viewed as "inner convictions, hunches, gut feelings, a sixth sense about something without evidence or knowledge" (Wong, 2006 cited in McGregor, 2014).

As it has been identified earlier, strengthening attention to the question of meaning interpretation in cognitive linguistics was warmed up by "the narrative turn" in the 1980s of the XX century and simultaneously sprung in several discernible directions: in psychological research on language processing, in literary theory of reception by the "implied reader" (Iser, 1974) and philosophical nature of knowledge and cognition. The research on meaning interpretation in fiction as a complex process has been widely influenced by scholarship on language as a sign system (Ogden \& Richards, 1923; Benveniste, 1971) and the nature of its semiotic representation" (Peirce, 1868; Morris, 1964). Recognizing the potential of semiotic interpretation, scholars assigned it to different language categories: first, to words or lexemes; then to morphemes, words, word combinations, sentences (Ferdinand de Saussure, Louis Hjelmslev, André Martinet); then to all constituent parts of the language, including phonemes, semes, having a representative function of materiality. Finally, bringing into the focus the notion of "sign situation" (by C. S. Peirce) allowed putting a three-componential model of sign representation into the basis of semiotics and its application to textual analysis of fiction.

According to Charles S. Peirce, signs become actualized when they represent something other than themselves, in other words, signs always depend upon something other than themselves (Herman, 1999: 91). This quality of "sign otherness" is realized or mediated through the relational context of their cultural and historical antecedents. Thus, the concepts of mediation and triadicity constitute the main difference from the Saussurian two-componential sign definition. Essentially, Peirce's idea of triadicity finds itself in the dyadic relationship between the sign itself and the signified, who refers to the sign's meaning (Ibid.). This dialogical and dynamic conception of interpretation can be represented in a 
triadic relation between a representamen $(\mathrm{R} 1)$, an object $(\mathrm{O})$, and an interpretant (I) or $\mathrm{R} 2$ (a representamen 2).

In a psycholinguistic perspective, Peirce speaks of the relationship between the signs of two minds, ascribing consciousness to the author and the interpreter (Sonnenhauser, 2008: 329). This consciousness, according to Peirce, represents not a knowledge of something, but a sort of interaction between the outer and the inner world, performing the function of self-control (Peirce, 1967: 318). Interestingly, this interaction of signs presupposes the emergence of communicative agents of semiosis (cf. Maturana and Varela, 1980), defining it as a dynamic system, producing and reproducing itself in constant exchange with context (environment) as a part of sign universe (Scheibmayer, 2004:323). Thus, the process of sign interpretation is seen as indefinite semiosis, as the endless generation of meanings by the interpretant. So, interpretant's cognitive operations in generating new hypotheses and the nature of this type of reasoning per se constitute the point of interest for literature and semiotics. Therefore, it is necessary to define these operations and their role in meaning interpretation.

Psychologists and neuroscientists investigated the mental and neural mechanisms of the reader at work during the interaction with fiction, conceptualizing it through Theory of Mind (Zunshine, 2015), like mind reading, or a neurophenomenology (Armstrong, 2013: 25). After decades of reader's reduction to a disembodied notion and "the death of the author" by Roland Barthes, the status of the reader and the author were redefined in the terms of "subjectivity theory" and became a category of modern humanitarian knowledge paradigm. Subjectivity is a concept of selfhood, developed and articulated through the acquisition of language, gained the attention of the researchers from the point of its selfsubjectification in cultural, epistemological, ideological, and social discourses (Larrain \& Hayes, 2019). From the psycholinguistic perspective, the problem of the reader's subjectivity lies within the spectrum of research on prognostic human ability and the question of anticipation of sign information, means of its 
transforming, coding, and decoding, i.e. theory of information exchange and semiotics.

Seeing the source of subjectivity in most utterances of language as the interpretation of signs by agents (reader, author), this paper aims to describe a model of reader's abductive information processing, regulated by a sign-centered approach to communication (C. S. Peirce), where subjectivity is considered to be inherent in the very essence of signs (Sonnenhauser, 2008).

To reach this objective, a more scrupulous look is needed at the threecomponential semiotic model of argument by Charles Peirce as a hypothesis; generated by a human for implicit meaning processing. Abduction here is viewed as a type of reasoning and part of the communicative process, playing a leading role in the reader's processing of narrative discourse, and fiction world creation/disruption. Therefore, the following research questions are formulated:

1. What is the nature of sign interpretation in its application to textual analysis?

2. What linguistic factors determine the use of abduction in the interpretation of signs?

3. How to apply abductive reasoning in the process of reading?

The paper is structured as follows: Method and Procedure Section, where the course of research is represented in the context of the modern theory of narrative. The role of abductive reasoning and its context-dependence on the semantic network is represented in examples of a four-stage pattern of abduction used in the interpretation of narrative short story are given in the Results and Discussions section. The paper crowns with Conclusions, situating the findings of the present research in a wider scope of an interdisciplinary approach to meaning processing and fiction interpretation.

\section{Method and Procedure}

Investigation of the process of meaning perception through hypothesizing and abstraction necessitated the application of integrated methods of semiotics, 
linguistics, and psycholinguistics. The role of presuppositions and shared knowledge of the author/sender and the reader/receiver of information is considered a common point of interest for both linguistics and psycholinguistics, and thus, relevant to our research of the subjective side of meaning, rooted in sign interpretation. The semiotic framework of triadic sign interpretation of Peirce is used to simulate the four-stage process of abduction on the part of the interpretant/the reader in the course of textual analysis. Then, using Hebert's modification (Hebert, 2011), each of the three terms of semiosis is further subdivided following the three categories: thus, we distinguish firstness, secondness, and thirdness in the representamen, in representamen-object relations, and in the way the interpretant implements the relationship between representamen and object. As in terms of theoretical conventions, the interpretant is a semiotic triad corresponds to the functions of the reader/interpreter, the main unit for analysis of subjectivity lies within the sign trichotomy of the interpretant, where the sign is called (1) a rheme (firstness), (2) a dicisign or dicent sign (secondness) or (3) an argument reasoning (thirdness).

While being interpreted, the representamen tends to trigger the interpretant, which in turn, becomes the representamen and triggers another interpretant, making the process of interpretation unlimited. The notion of habit was extrapolated from the sphere of psychology to denote the border (the final interpretant) for infinite interpretations $(\mathrm{N})$ in the process of generating hypotheses: "Peirce calls the final logical interpretant our habit of attributing a certain signification to a certain sign in a certain context with which we are familiar. Force of habit temporarily freezes the infinite recursivity of one sign to other signs, which allows interlocutors to quickly reach consensus on reality in a given communication context" (Hebert, 2011:194).

Analysis of argumentative reasoning followed the four-stage process (Hebert, 2011:196) and then was summed up according to the type of reasoning pattern (abduction, induction, deduction), and compared to the type of event and its position in the text. 
Material for study constitutes narrative episodes (by the definition of Herman (Herman, 1999), and events as constituent parts of episodes of narrative fiction of the XX century, disclosing gender issues in the society and family: "Happy Endings" (1983) by Margaret Atwood. The choice was conditioned by the thematic parallel to narrative plot construction, describing the questions of marriage/happy living from the socio-cultural paradigm of the XX century and the theoretical issue of modern narratology in plot construction and story world creation. The decisive factor is that the story contains episodes calling for inductive and deductive reasoning, provoked by abduction, leading to a tentative conclusion, summed up with a coda.

\section{Results and discussion}

To follow the process of abductive reasoning in reading, we had to define sign interpretation principles and the role of the interpretant in the three-componential semiotic model of sign, suggested by Charles Peirce. In other words, we had to look at the endless loop of interpretation between the narrative and the consciousness of the interpreter. But, unlike hermeneutic view on the reader's infinite interpretation, fancying an idealized reader as a receiver of the information embodied in the text, this paper strived at finding regularities and differences in the process of meaning inference among different chunks of narrative episodes. While abduction as a third type of argument was introduced by Peirce into the diagram of semiosis, the object of the study constituted these positions of the interpretant in the four-stage process of abductive reasoning:

1) we encounter a curious fact, which we cannot explain based on our prior knowledge;

2) we formulate a hypothesis that may explain the fact;

3) next, we apply the hypothesis deductively, and we may infer the consequences that follow from it; 
4) by using a kind of induction, or making generalizations based on several positive test results, we conclude that the results verify the hypothesis, at least provisionally, until there is proof to the contrary (Hebert, 2011:196).

Firstly, the definition of a curious situation as a starting point of abduction became the criterion for defining a type of narrative situation for analysis. We see it as a certain correspondence to David Herman's term "world disruption" as he names it, following Vladimir Propp ([1928]1968). But when Propp qualifies disruptive events to be the motor of narrative, Todorov ([1978] 1990) tries to see in disruptive events the source of reader's intuitive guessing and inferences about kinds of agency characters have in the story world (Herman, 1999: 20). Moreover, if to follow Bruner (1991), the narrative is seen as a certain type of cognitive and communicative strategy for navigating the gap, based on personal experience and comparing it with the actual state of facts. Thus, in the course of analysis, we differentiated between such structural components of narrative as "episode" - "a bounded, internally coherent sequence of situations and events" (Herman, 1999), and "events that can be chained together with other such narrative units to form larger narrative structures" (Ibid.). From the semiotic perspective of Peirce, any coherent unit of information could be understood as a sign: "Any thing or phenomenon, no matter how complex, may be considered as a sign from the moment it enters into a process of semiosis" (Hebert, 2011:193).

In "Happy Endings" (1983) by Margaret Atwood (Madden, 2002), the reader is provoked by the abductive introduction to the text from the very beginning. By introducing the following syllogism:

e.g. John and Mary meet.

What happens next?

If you want a happy ending, try A (Madden, 2002:168).

Since the beginning of the story is a strong position in the architecture of storytelling; it is a very important element in the semiotic interpretation of the whole text as a system of signs. On the level of connotations, the reader is occupied with several cognitive operations: abduction, induction, and 
substantiation. The first sentence sends to the reader to the notion of "meeting" in its denotation: /meeting/ n. 1. Coming together, 2. Assembly of people, gathering (The Oxford essential dictionary, 1998: 372). While in the semiotic analysis we deal with sign interpretation, the word "meeting" becomes a part of the event, an episode, which will be further employed by the author for evolving other narrative fragments (A, B, C, D, E, F).

The intriguing question "What happens next?" can be put to each of the narrative parts, as a starting point for developing a storyline. Consequently, the same question serves coherence purposes of all six sub-narrative parts and invites inductive thinking on the side of the reader (so typical for contemplation about the reasons of the situation and planning possible hypotheses for interpretation).

In "Happy Endings" the aim of the maximal economy of explicit information is reached by a concise, almost mathematic style of narration, resembling a kind of equation: "If you want a happy ending X, try A". But the author's reference to mathematical logics provokes further development of this equation dispassionately, devoid of any emotional coloring, despite the use of the words naming the processes and emotional reactions ("falls in love", "gets run down", "crying is bad for your health", "can’t believe", "Mary is hurt", etc.).

The third-person narration here serves the purpose of maximal distancing from the emotional side of the events for the sake of meaning-making of facts and events in a certain sequence (as a plot): Mary and John fall in love and get married (in story A); Mary falls in love with John but John doesn't' fall in love with Mary (story B); "John, who is an older man, falls in love with Mary, and Mary, who is only twenty-two, feels sorry for him because he is worried about his hair falling out" (story C); "Fred and Madge have no problems" (story D); "Yes, but Fred has a bad heart" (story E); "If you think this is all too bourgeois, make John a revolutionary and Mary a counterespionage agent and see how far that gets you" (story F).

Symbolically, each of the narrative sub-parts constitutes the whole story narration, as the first story A introduces the main characters and one scenario of 
plot development (the happiest one, as the author suggests). Each part has two main characters: John and Mary, and different complications of the events around them in every following part. Though the macro-storyline lacks coherence in terms of temporal sequencing, the reader is involved in hypothesizing about possible plot development together with the author, who is testing various versions and scenarios of the events. Schematically, the pattern of abductive reasoning on the side of the reader can look as follows:

Story A: If you want a happy ending, try A, because the first condition in the equation of a happy life is mutual love.

Story B: If you want a happy ending, don't try B, because the first condition of mutual love is absent from the very beginning and it leads to a tragic story of Mary's suicide and further marriage of John with Madge.

Story C: If you want a happy ending, don't try C, because the first condition of mutual love is absent again, deteriorated by a big age difference and adultery, relations lead to a tragic killing of Mary and his boyfriend, and John's suicide. Madge marries Fred and it is equal to Story A.

Story D: If you want a happy ending, try D, but you will come through various hardships on your way to happy A.

Story E: If you want a happy ending, you should be ready to face the health problems of your partner, accept death and find your way to charity until the end of A ("Eventually they die") (Madden, 2002:168).

Story F: If you want a happy ending, you will still end up with A, because the endings are all the same, suggests the author.

In the course of inductive reasoning, the reader comes to the idea that happy endings in all versions of the story are all the same as in A: where Mary and John die. The allusion to a well-known pattern of plot development in all fairytales: "They all lived happily ever after". The conclusion, which follows all sub-narrative parts, sums up this idea: "You'll have to face it, the endings are the same however you slice it", but "the stretch in-between" is "the hardest to do anything with" (Madden, 2002:170). Thus, from the very beginning of the story, the reader starts 
hypothesizing an attempt to answer the question: If I want a happy ending, what shall I do? Successfully led by the narrative cognitive pattern of equation solving, the reader follows events complications as "a story in-between", and in such form, reaches an effect of coda, leaving the reader with a solid ending.

But in "Happy Endings", Margaret Atwood creates a coda, which is not satisfying for the reader. By asking the question "What happened next?" at the beginning of the story, the narrative goes in a logical search for a correct answer. But unlike traditional coda, the ending of the narrative doesn't provide the reader with the satisfaction (i.e. the correct answer). Moreover, the story wraps up with a new complication, provoking readers' further reasoning:

e.g. That's about all that can be said for plots, which anyway are just one thing after another, $a$ what and $a$ what and $a$ what. Now they are How and Why (Madden, 2002:170). An inference pattern of the reader's reasoning here fully corresponds to Peircian pattern of abduction: The surprising fact, $C$, is observed; But if A were true, $C$ would be a matter of course, Hence, there is reason to suspect that $A$ is true (Peirce, 1931-1966, 5:189). This scheme of reasoning undergoes the following restructuring in terms of sign interpretation. The question word "what" in the interrogation of the author and the opposing question words "How?" and "Why?" where the surprising fact C ("what happens next?") acquires its signification in the course of interpretation.

In semiotic terms, the first narrative A becomes an object $(\mathrm{O})$, and the following narratives $(B, C, D, E, F)$ are generated by the interrelation between the environment (the context) and narrative A. Correspondently, on the level of narrative interpretation, the reader deals with the multiplicity of hypotheses, generated by the relations of the interpretant and the object. It justifies the fact of circular repetitions of the basic scenario of story $\mathrm{A}$ in the following later stories (B, C, D, E, F). Mainly, these multiple relations between the aspects of a sign, affected by the personal experience of the reader (umwelt) can be viewed as manifestations of subjectivity (Sonnenhauser, 2008) in a form of hypothesizing. While the sign situation establishes a constant exchange of information with the context 
(environment), narrative interpretation can be defined as a self-determined dynamic system, i.e. semiosis (Scheibmayer, 2004: 323).

\section{Conclusions}

Textual analysis and interpretation of narrative in the context of interdisciplinary approach necessitates the application of findings of semiotics as the science of signs and their interpretation. In its relation to fiction analysis and our research questions, the semiotic approach suggested by Peirce has the following advantages: 1) it is general; 2) triadic, and 3) pragmatic. All these qualities, taken together allow combining three aspects of sign interpretation in one research: pragmatics (the domain of the interpretant), semantics (the domain of the object), and syntax (the domain of the representamen). By doing so, this paper synthesizes the findings in the Theory of Mind, cognitive poetics, and postclassical narratology, and shifts the angle of attention from the endless "hermeneutic circle" of interpretation to reasoning operations of the reader's sensemaking: abduction, induction, deduction. It has been noticed, that the deductive hypothesis (the abduction) serves as a source of subjectivity, leading to the dynamics of semiotic interpretation and textual analysis (RQ1).

In the triadic argumentation model by Charles S. Peirce, the notion of "surprising event" is the first condition for abductive reasoning. In the course of our analysis, "surprising events" in fiction corresponds to the notion of "world disruption" and is viewed as a pre-condition, determining the use of abductive reasoning (RQ2). In terms of fiction reading and interpretation, the semiotic framework of abduction is seen productive for its distinction between plausible (as inference to its best hypothesis) and possible hypotheses (as an unlimited semiotic meaning generation), which might help in strengthening students' literary competence and ability to hypothesize while reading fiction (RQ3). The current state of research calls for more empirical studies, involving "think-aloud protocols" of the readers, coupled with insights into the level of students' awareness of cognitive processes they use while reading the text. 


\section{References}

Armstrong, P. (2013). How Literature Plays with Your Brain. The Neuroscience of Reading and Art, Baltimore, Johns Hopkins University Press

Benveniste, E. (1971). Problems in General Linguistics. Florida: University of Miami Press.

Bruner, J. (1991). The Narrative Construction of Reality. Critical Inquiry 18, 1-21. Hébert, L. (2011). Tools for Text and Image Analysis: An Introduction to Applied $\begin{array}{lllll}\text { Semiotics. } & \text { Retrieved } & \text { on } & \text { 28.02.2020 }\end{array}$ http://www.signosemio.com/documents/Louis-Hebert-Tools-for-TextsandImages.Pdf'

Herman, D. (ed.) (1999). Narratologies: New Perspectives on Narrative Analysis, Columbus, Ohio State University Press.

Iser, W. (1974). Implied reader. Baltimore, Johns Hopkins University Press.

Larrain, A., \& Haye, A. (2019). Self as an Aesthetic Effect. Frontiers in psychology, 10, 1433. doi.org/10.3389/fpsyg.2019.01433

Madden, F. (2002). Exploring Fiction: writing and thinking about fiction. Addison Wesley Longman, Inc.

Maturana, H. \& Varela, F. (1980). Autopoiesis and Cognition. Dordrecht: Reide

McGregor, S. L. T. (2014). Abductive reasoning in everyday life: Implications for Home Economics. Kappa Omicron Nu FORUM, 19 (1).

Morris, C. (1964). Signification and Significance: A Study of the Relations of Signs and Values. Cambridge, Mass.: MIT Press.

Ogden, C. K. \& Richards, I. A. (1923). The Meaning of Meaning. 8th edn. New York, Harcourt, Brace \& World, Inc.

Paltridge, B. et. al. (2009). Teaching Academic Writing. An Introduction for Teachers of Second Language Writers. The University of Michigan Press, Ann Arbor. 
Peirce, C. S. (1931-1966). The Collected Papers of Charles S. Peirce, 8 vols., C. Hartshorne, P. Weiss, and A. W. Burks (eds.). Cambridge: Harvard University Press.

Peirce, C. S. (1967). Manuscripts in the Houghton Library of Harvard University. Amherst: University of Massachusetts Press.

Pierce, C. S. (1868). Some consequences of four incapacities. Journal of Speculative Philosophy, 2, 140-157.

Propp, V. ([1928] 1968). Morphology of the Folktale, 2nd edn, trans. L.Scott; Austin: University of Texas Press.

Scheibmayr, W. (2004). Niklas Luhmanns Systemtheorie und Charles S. Peirces Zeichentheorie. Tübingen: Niemeyer.

Sonnenhauser, B. (2008). On the linguistic expression of subjectivity: Towards a sign-centered approach. Semiotica 172, 1/4, 323-337 doi.org/ 10.1515/SEMI.2008.102

The Oxford Essential Dictionary (1998). Berkley Books, New York.

Todorov, T. ([1978]1990). Genres in Discourse. Trans. C. Porter. Cambridge: Cambridge University Press.

Walsh, F. (1972). K. T. Fann, Peirce's Theory of Abduction. The Hague: Martinus Nijhoff, Philosophy, 47 (182), 377-379. doi.org:10.1017/S003181910005600X Zunshine, L. (2015). The Oxford Handbook of Cognitive Literary Studies, Oxford, Oxford University Press. 